\title{
Tempo, filme, memória: a invenção do passado em Aitaré da Praia
}

\section{RESUMO}

O levantamento preciso da implantação de figuras de linguagem no contexto do cinema brasileiro resta a ser feita. Cópia alienada dos modelos europeus e americanos do norte ou ajuste criativo, essa implantação pode ser verificada nos exemplares restantes do primeiro cinema nacional. Aqui, propomos avaliar o uso do flashback num dos clássicos do Ciclo do Recife, Aitaré da Praia, realizado em duas versões (Gentil Roiz, 1925; Ari Severo, Jota Soares e Luís Maranhão, 1927). Esse estudo exploratório pretende fazer uma primeira categorização do emprego da figura nos filmes brasileiros da década de 1920.

\section{PALAVRAS-CHAVE}

cinema

linguagem cinematográfica

flash-back

\section{ABSTRACT \\ Understanding how the early Brazilian Cinema incorporates figures of cinematic language is a work that still wait to be made. The process could be observed in the few preserved copies of the firt national films, to check if this incorporation was an alienated copy of European and American models or a creative peripheral adjustment to them. In this paper we try to observe the use of the flash-back in one of the classics of the "Ciclo do Recife" period (1923-1931), Aitaré da Praia (Gen- til Roiz, 1925; Ari Severo, Jota Soares e Luís Maranhão, 1927), in an exploratory study that aims to establish a first categorisation of the flash-back in the Brazilian films in the 1920's.}

\section{KEY WORDS}

cinema

cinematic language

flash-back

\section{A representação do tempo como marca autoral}

Nem na literatura nem no cinema, os deslocamentos no fluxo temporal do relato são pontos pacíficos entre os narratólogos. Nossa perspectiva adota o princípio antropomórfico defendido por François Jost em Un monde à notre image, considerando que, no cinema, boa parte da estratégia narrativa dispensa a contribuição de instâncias narrativas associadas à diegese e é controlada pelo espectador, que assume o destino da narração e constrói o autor, constituindo-o inclusive enquanto um corpo. Ao refletir sobre como o cinema conta histórias, Jost parte da engenharia literária descrita por Gérard Genette (em Figures III, de 1972) e defende que, no cinema, além da focalização, é necessário perceber o que ele chamou de ocularisação e de auricularização. É fácil perceber que Jost descarta o modelo narratológico imanetista característico de Metz (1991) e, antes dele, de Gaudreault (1988) para desenvolver, sob a inspiração de Jaap Lintvelt (1992), um modelo antropomórfico, centrado no espectador e na prelavência do autor construído, operando no quadro de uma polifonia enunciativa.

O que há de essencial no esforço de Jost é a reintrodução da figura do autor no contexto do pós-estruturalismo. Jost consegue fazer essa revisão mantendo aquilo que havia de essencial na semiologia - sua insuperável capacidade de dar conta das descrições textuais e, desse modo, fugir do excesso de análise conteudística que marca a posteridade teórica do cinema, incluindo os esforços dos Estudos Culturais. Do mesmo modo, o privilégio ao espectador na operação narrativa é radical e permite perceber como, afinal, a narratologia deve ser necessariamente diversa quando aplicada à literatura e ao cinema. Há, ainda, em Jost, a reafirmação da impossibilidade de distinguir, no campo operatório do filme, entre enunciação e narração, na medida em que o que chamamos de narração é sobretudo um conceito especializado para dar conta da enunciação narrativa.

Mas o que é, rigorosamente, o processo de antropomorfisação narrativa em Jost? De um lado, como ele afirma (p. 30), são "entidades que surgem, sem necessidade de serem personalidades completas : precisam apenas ter intenções, ou mesmo coincidir com elas" ${ }^{\prime 1}$. O antropomorfismo seria "um produto dessa forma particular de imaginação que é a função fabuladora. Essa faculdade do espírito está na origem do romance, na medida em que ela inventa personagens dotados de autonomia e que permite ao leitor de crer nelas" 2 . Cabe ao espectador decidir, em fim de percurso, qual a intenção do autor na articulação de suas figuras: informativa, artística ou, simplesmente, erros desprovidos de senti-

\author{
Paulo C. Cunha Filho \\ Professor do Programa de Pós-Graduação em Comunicação Social da \\ UFPE/RE/BRI e pesquisador do CNPq \\ paulo@ufpe.br
}


1 Os letreiros iniciais e abertura funcionam para apresentar a praia do Tatiá (na verdade, a praia de Piedade, deserta na época) e os principais personagens. Há, logo no início, uma primeira idéia da oposição entre Aitaré e Traíra, ambos interessados por Cora.

2 Na casa de Dona Guilhermina, a mãe de Cora, a familia fala da possibilidade de uma mudança para o Recife.

3 Na praia, as duas duplas antagônicas (Aitaré/Zé Amaro e Traíra/Zeno) partem para pescar. Cora se despede de Aitaré e aguarda na praia. Ambos os barcos retornam.

4 Outra vez na casa de Dona Guilhermina, a mãe de Cora revela os motivos de sua oposição a relacionamento entre ela e Aitaré: o passado da familia do pescador, violenta e descendente de indígenas. No meio do diálogo, um flashback (a partir de agora FB1) mostra cenas divers as de atos de violência praticados pela familia de Aitaré.

5 Na praia, Cora conta a Aitaré o que ouvira sobre o seu passado. Também nesse momento, mas de forma rápida, outro flash-back (a partir de agora FB2) repetem as cenas de violência da familia de Aitaré.

6 Discussão verbal seguida de luta corporal entre Aitaré e Traíra. Aitaré leva a melhor.

7 Festa na casa do Capitão Afonso. Aitaré briga com Zeno (comparsa de Traíra) e leva vantagem outra vez.

8 Tempestade. Mesmo com o tempo ruim, Aitaré resolve sair sozinho para pescar com sua jangada. Zé Amaro recusara-se a acompanhá-lo.

9 Na casa de dona Guilhermina, Zeno leva a má notícia: Aitaré fora pescar no meio da tempestade. Cora se desespera.

10 Na praia, Cora e Zé Amaro esperam o retorno de Aitaré.

11 Na jangada de Aitaré, ainda em alto mar, dois náufragos (Glória e seu pai) são resgatados. Um flash-back (a partir de agora FB3) mostra os náufragos antes da tempestade, lendo no convés de um iate de luxo.

do. Jost identifica quatro posições enunciativas:

* Enunciação cinematográfica - a que remete a um "suposto realizador", cujas intenções discursivas são explícitas (o exemplo é os contre-plongées de Orson Welles);

* Enunciação narrativa - que se refere ao narrador impessoal e anônimo que conta uma história (no caso, um narrador implícito, como no travelling final de Cidadão Kane, revelando ao espectador o segredo da palavra rosebud);

* Enunciação fílmica - que remete a um sujeito empírico, muito característico nos documentários ou nas reportagens;
12 Já na praia do Tatiá, Cora ajuda Glória a recompor-se, vestindo-a e penteando-a.

13 Aitaré faz dois braceletes de casca de coco, fica com ume presenteia Cora com o outro, sob o olhar enciumado de Glória.

14 Depois de se lamentar com o pai que Aitaré não a amava, Glória conversa entristecida com Aitaré.

15 Mais uma vez, Zeno vai à casa de dona Guilhermina. Mente, dizendo que Glória e o pai haviam partido, e que Aitaré partira com eles. Um flash-back (a partir de agora FB4) é utilizado para revelar o que de fato ocorrera: um barco do Recife chegada ao Tatiá para levar Glória e o pai de volta ao Recife, sem a participação de Aitaré que havia viajado por outras razóes.

16 Revoltada, Cora se retrai e se recusa a ouvir de Zé Amaro o que de fato ocorrera.

17 Cora parte com o irmão e a mãe para o Recife, num "decauville" - espécie de pequeno vagão de tração marual que anda na linha férrea. Cora, virada para trás, lembra de Aitaré num flash-back (a partir de agora FB5).

18 Aitaré retorna ao Tatiá, procura por Cora e recebe a notícia da partida da amada através de Zé Amaro.

19 Aitaré decide aceitar o convide do pai de Glória e também parte para o Recife.

$20 \mathrm{Na}$, chegada ao Recife, um Aitaré desajeitado na cidade grande precisa de ajuda até para tocar a campainha da casa de Glória.

21 Letreiro "Cinco anos depois". Cora vai às compras com o irmão e vê uma pessoa que lembra Aitaré. Umflash-back (a partir de agora FB6) evoca imagens de Aitaré no Tatiá.

22 Aitaré aparece aburguesado, lendo uma revista de moda no terraço da casa do pai de Glória.

* Autor construído - representa o narrador como ser do mundo dotado de sentimentos que ele tenta comunicar

A grande mudança proposta por Jost é a reivindicação da leitura do filme enquanto "obra", na medida em que, durante muito tempo, evitando antropomorfisar as instâncias narrativas, o processo enunciativo do filme foi considerado "impessoal" (Cf. Bordwell, 1985 e Metz, 2001), adotando uma postura da teoria literária: Jean Ricardou (1978) pretendia ser o romance uma "fábrica inumana", no qual o texto "podia se engendrar dele mesmo"... Jost é límpido na contestação do princípio da impessoalidade: "Há na narração, ou melhor atrás dele ou diante dele, alguém que conta, que é o narrador. Além 
do narrador, há alguém que escreve e que é responsável de todo o seu aquém. Esse, grande novidade, é o autor"3.

\section{A constituição enunciativa espectatorial do flash-back}

Se o espectador constrói o autor, é a partir do mecanismo de enunciação (o uso das figuras da linguagem cinematográfica) que ele opera e fecha o processo narrativo. Ora, como se sabe, as figuras que os retóricos e os teóricos da literatura chamam de analepse e de prolepse inspiraram, na cena cinematográfica, as figuras que receberam os nomes simplificados (e claramente insuficientes) de flash-back e de flash-foward. No romance ou no filme, essas figuras indicam as maneiras através das quais o discurso narrativo reordena o tempo numa dada história: retornando a um ponto "anterior" (analepse) ou saltando até um momento "posterior" na seqüência cronológica de eventos (prolepse).

As figuras são antigas, guardadas as devidas propor-
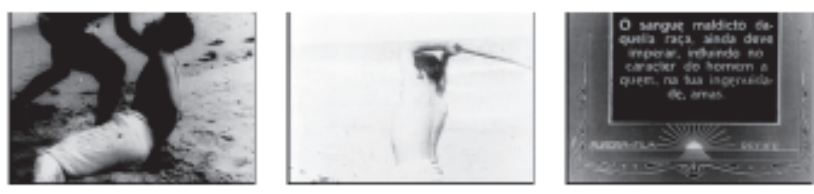

ções temporais, tanto no caso da linguagem literária quando no caso da linguagem cinematográfica. Na narrativa literária, por exemplo, variações da prolepse estão há muito registradas nas profecias ou na tragédia, como quando Sófocles antecipa a Édipo que, no fim da história, ele dormirá com a mãe e assassinará o pai. Mas a figura que nos interessa no quadro deste artigo é a analepse cinematográfica (ou o flash-back), da qual Bordwell e Thompson (2002, p. 585) dão uma definição precisa: "uma modificação da ordem da história através da qual a narração retorna num acontecimento anterior à ação".

Essa figura corresponderia assim a um deslocamento do eixo temporal que determinaria a produção de uma "decronologia". Dada uma ordem linear ABCDE, teríamos uma alteração do tipo AC(B)DE. Ora, se a literatura pode lançar mão de diversos modos de expressar o passado (passado, imperfeito, mais-que-perfeito, entre outras variações), no cinema, há apenas um tempo - "o presente, no seu valor imperfeito" (Gaudreault e Jost, 1990, p. 109), o que transforma oflash-back num procedimento crucial para a representação do tempo no relato fílmico. Nesse sentido, a variedade do flash-back no cinema tem de buscar sua origem em outros elementos, para além da variação verbal da literatura. De alguma forma, ao lado de outros procedimentos igualmente estruturais, o flash-back permitiu ao cinema tornar-se uma forma narrativa complexa e, ao mesmo tempo, narrativamente diferente da literatura e do teatro.

Os primeiros flash-backs conhecidos (e reconhecidos como tais, fora portanto, do que Jost chama de "erro desprovido de sentido") no cinema são de 1911-1912, tanto nas produções americanas quanto nas européias. De acordo com Maureen Turim (1989), a intensificação do uso do flash-back pode estar relacionada ao que ela interpretou como "uma compensação da ausência de som e uma antecipação da chegada do som" (p. 49). O flash-back inicial (sobretudo em Griffith, Murnau, Lang ou Wiene) dialoga intensamente com os letreiros, responsáveis por habituar as platéias aos deslocamentos temporais e outros artifícios da linguagem do cinema. Só aos poucos, provavelmente apenas no final do período dito mudo, o flash-back efetivamente se autonomiza e se incorpora à enciclopédia de figuras relativamente estáveis do espectador.

Não se trata de um procedimento narrativo simples, na medida em que cabe ao flash-back permitir que a ordem linear a partir da qual os eventos aconteceram (a ordem da história) possa ser expressa numa ordem alterada (a ordem do discurso). Mais ainda: que a ordem do discurso seja superior à ordem da história. O flash-back se configura, nessa perspectiva, como um dos principais modos do filme, capaz de permitir ao espectador se saber projetado num retorno narrativo - e percebendo que, afinal, num filme, a ordem da história e a ordem do discurso não se ordenam que diante dos seus olhos. A complexidade do flash-back como figura pode ainda ser considerada na determinação técnica que aos poucos foi caracterizando o seu emprego. Como lembra Turim (1988), o flash-back é apenas a ponta de um iceberg narrativo, se associando frequentemente a: (1) movimentos de câmera (travellings ou panorâmicas rápidas), acompanhados por certos padrões musicais e/ ou de superposição; (2) antecipação e/ ou mixagem de sons (os sons do passado invadindo as imagens do presente), superposição sonora, distorções da trilha sonora (eco, alterações de volume ou de textura), voz off (deslocamento da instância enunciadora, capaz de tornar-se "voz interior"), texto do narrador com marcas de transcendência ou de onisciência; (3) inversões cromáticas (da cor para o preto \& branco, por exemplo, ou para um padrão de cor saturado); (4) articulação de diálogos (conversas com reminiscências, por exemplo); (5) marcas corporais da interpretação dos atores (olhares perdidos, olhares para a câmera, entre outros); (6) jogo de foco/desfoco das imagens; (7) efeitos cenográficos múltiplos (calendários, relógios, objetos que remetem ao passado, por exemplo).

A questão que se coloca aqui, portanto, é: com que articulações e funcionalidades a figura do flash-back foi empregada no cinema brasileiro dos anos 20 ?

\section{Descrevendo Aitaré}

O Ciclo do Recife (1923-1931) se constitui como o primeiro grande movimento cinematográfico na história do cinema pernambucano e o mais intenso ciclo cinematográfico regional do início do século XX na América Latina, durante o qual foram produzidos 13 filmes de ficção 
de oito diretores que faziam parte de um grupo de cerca de 30 jovens (quase todos entre 20 e 25 anos na época) atraídos pela realização cinematográfica.

Vista de longe, a relativamente extensa produção do Ciclo do Recife aparenta ter sido marcada pelo entusiasmo de um grupo de produtores da periferia do capitalismo. Mesmo enfrentando grandes dificuldades - que iam desde questões propriamente tecnológicas, como a revelação da película, até problemas de exibição e distribuição dos filmes -, foram fundadas no período nove firmas produtoras diferentes e rivais. Todas elas faliram, e mesmo a Aurora Film, considerada a mais importante delas por ter produzido os dois maiores clássicos do cinema mudo pernambucano (A filha do advogado e Aitaré da praia), foi vendida duas vezes antes de fechar definitivamente ${ }^{4}$.

\section{0 que procuramos mostrar em} Aitaré da Praia é que o cinema brasileiro dos anos 20 era capaz de empregar o dispositivo do flash-back de forma diversificada, dando à enunciação narrativa uma sofisticação.

Quando se pensa na fórmula complexa a partir da qual o Recife organiza a sua pioneira representação cinematográfica, é nítida a sensação de que os filmes serviram de veículos para a incorporação de novos modelos de comportamento social. Essa tarefa não foi exclusiva dos filmes já que as revistas femininas, o teatro de costumes e as revelações de viajantes também colaboravam nesse processo. Mas coube aos filmes do Ciclo associar, de forma mais explícita, a cena local e a adoção dos novos padrões.

Aitaré da Praia foi produzido no apogeu do Ciclo do Recife (o biênio 1925-1927), no qual são rodados 8 dos 13 filmes, incluindo a outra produção com quem rivaliza em termos de sofisticação: A Filha do Advogado (1926). Há duas versões do filme Aitaré da Praia. A primeira, de 1925, foi dirigida por Gentil Roiz, com fotografia de Edson Chagas, a partir de um roteiro de Ari Severo, sob o selo da Aurora Filme. Dois anos depois, com a falência da Aurora, a Liberdade Filme, através de Edson Chagas, adquiriu o negativo já incompleto e refilmou algumas partes extraviadas. Na versão de 1927, a direção foi de Ari Severo, Jota Soares e Luis Maranhão. A cópia que examinamos é referente à versão tardia.
O filme teve dois financiadores: na primeira versão, Joaquim Tavares; na segunda, Edson Chagas. O elenco reunia alguns nomes centrais do Ciclo do Recife: Ari Severo (Aitaré), Jota Soares (Traíra), Almery Steves (Cora), Rilda Fernandes (Glória), Mário Freitas Cardoso (Zé Amaro), Cláudio José (Zeno), Rosa Temporal (Mãe de Cora), Queirós Coutinho (Pai de Glória), Tito Severo (Irmão de Cora), entre muitos extras. Na segunda versão, devido às refilmagens de cenas perdidas, apareceram como atores Pedro Neves e Edson Chagas.

Aitaré da Praia pode ser classificado, como a maior parte da produção do Ciclo do Recife, como um longametragem (tinha "oito partes", como se apregoava na ocasião) de aventuras e peripécias - o termo usual nos anos 20 seria "filme de enredo", em oposição aos "naturais" (ou documentários). Tinha, entretanto, uma peculiaridade marcante com relação aos filmes anteriores do Ciclo do Recife: incorporava temas regionais (no caso, a vida dos jangadeiros) e explorava com certa graça a relação tensa entre a mentalidade urbana e a mentalidade do interior.

Duas duplas antagônicas de jangadeiros Aitaré/Zé Amaro (bons) e Traíra/Zeno (maus) giram em torno da mocinha Cora. A disputa entre Aitaré e Traíra pelo amor de Cora se complica com o aparecimento, na afastada praia do Tatiá (localidade fictícia), de Glória, resgatada após o naufrágio do seu iate juntamente com o pai. Após algumas situações vividas na praia, Glória, Cora e posteriormente Aitaré instalam-se no Recife, onde se reencontram. No final feliz, o ex-pescador Aitaré casa-se com Cora. As "oito partes" de Aitaré da Praia podem ser divididas em 27 seqüências que dão conta do enredo:

\section{Brincando com o passado}

Aitaré da Praia coloca em operação, como vimos, seis flash-backs. A quantidade de vezes em que a figura surge nessa produção do Ciclo do Recife parece indicar um caso particular na filmografia brasileira do período. Se o flash-back já era usado nos filmes brasileiros dos anos 20, não se conhecem outros casos em que tenha sido empregado com tal insistência no período. Como a figura se insere na narrativa de Aitaré da Praia - e com que funcionalidade - é o que ainda hoje carece de interpretação, malgrado a forma central que eles ocupam na construção da trama.

Nas duas primeiras ocorrências, o flash-back é empregado de forma muito semelhante. Vejamos o caso inicial (FB1), em que temos uma cena simples, na casa de dona Guilhermina, que conversa com sua filha Cora sobre aquele pescador que desperta sua paixão. Num determinado momento, dona Guilhermina diz algo e Cora se espanta:

\section{- “Aitaré?!...”"}

O coronel Felippe Rosas se alegra:

- "Graças a Deus, ainda bem que encontro um meio 
de sahir daqui."

$\mathrm{O}$ resto do flash-back mostra o capitão do iate na praia, aceitando leva-los de volta ao Recife, e Glória afirmar:

- "Enquanto fasem as provisões, vou escrever um bilhetinho a Aitaré."

Glória chama Zé Amaro (companheiro de pesca de Aitaré), entrega o bilhete e pede:

- "Entregue isto ao meu savaldor e dê-lhe, juntamente, um saudoso abraço."

Glória completa:

- "Mil saudades à bella Córa".

Zé Amaro acena na despedida.

Nesse formato, FB4 não aparenta ambigüidade, nem funciona como discurso indireto, nem como construção autoral. Consiste na fórmula mais simples de um flashback tradicional, de recomposição narrativa, simplesmente invertendo a ordem do discurso. Aquilo que está em FB4 poderia vir antes da chegada de Zeno à casa de don Guilhermina, pois essa é a posição linear da seqüência no desenrolar da história.

Uma outra forma de representação do passado está na quinta e na sexta utilização de flash-back em Aitaré da Praia. Vejamos inicialmente FB5: quando decide partir para o Recife, magoada com Aitaré, Cora e sua família tomam um "decauville" (na verdade um pequeno vagão de tração humana, adaptado para trafegar nas linhas férreas da Zona da Mata canavieira do Nordeste). Sentada no banco traseiro, Cora tem o olhar perdido no horizonte e começa então a lembrar. São imagens dela própria, de Aitaré e do casal sentado sobre um troco de coqueiro, na praia do Tatiá.

Em seguida surgem as imagens evocativas, espécies de fantasmas do passado, mostrando, outra vez, Aitaré e o casal conversando na praia de Tatiá. Com cara de espanto, Cora diz ao irmão:

- "Perco minha felicidade se aquelle não for Aitaré."

Mário responde:

- "Vocês mulheres são impressionáveis..."

\section{Conclusão}

André Gaudreault (1988) tem afirmado que os estudos cinematográficos devem se proteger de uma ilusão: a de que o cinema sabe contar tão bem que se têm às vezes a impressão de que sempre foi assim. Esse autor também chama a atenção para outro fato paradoxal: se existe uma grande diversidade narrativa no cinema, essa variedade contrasta, no entanto, com o grupo relativamente pequeno de procedimentos e de figuras que são empregadas historicamente: planos, seqüências, certos movimentos de câmera, sons e efeitos. Toda a diferença - e que não é pequena - se dá entre os autores que empregam e relacionam esse pacote de fórmulas expressivas.

O Ciclo do Recife ainda está preso a uma fase muito inicial do que Tom Gunning (1979) chama de "cinema da narratividade contínua" ou de "cinema representativo-narrativo", para dar conta da forma cinematográfica de representar o mundo a partir de uma lógica calcada, o mais possível, na lógica do mundo real. Essa forma começa a ganhar corpo efetivo a partir de 1910, sobretudo com a contribuição genial de David Wark Griffith. Lembremos que Aitaré da Praia é de 1925 (primeira versão) e de 1927 (segunda versão).

\section{Se nossos olhos são mais} atraídos pelos "defeitos" e pela "ingenuidade" dos filmes do Ciclo do Recife, talvez seja porque estamos cada vez mais
desacostumados a representar o
nosso próprio passado.

Como sabemos, é a justaposição de dois ou mais planos que coloca, de fato, o problema do duplo parâmetro tempo e espaço no filme. Ou melhor, da articulação da ordem da história com a ordem do discurso. Dois planos sucessivos podem representar dois pontos de vista diferentes, dois espaços diferentes e dois tempos diferentes (assim como uma complexa combinação disso tudo). Dessa forma, o segundo plano poderá se referir a um tempo: (1) precedente ao tempo da ação do primeiro plano, flash-back; (2) levemente anterior ao do primeiro plano, superposição temporal; posterior ao do primeiro plano de maneira contínua, raccord contínuo; mesmo posterior ao do plano inicial, mais ou menos afastado dele, elipse.

O que procuramos mostrar em Aitaré da Praia é que o cinema brasileiro dos anos 20 era capaz de empregar o dispositivo do flash-back de forma diversificada, dando à enunciação narrativa uma sofisticação que geralmente negamos aos primeiros filmes rodados no país. Naquilo que pudemos analisar, o uso do flash-back como regaste, construção autoral, evocação ou como figura ordinária mostra bem como a representação do passado podia se vincular a esferas múltiplas da leitura do filme e que o espectador dos anos 20, no Brasil, assim como os realizadores, tinham atingido um patamar elevado de elaboração narrativa.

Se nossos olhos são mais atraídos pelos "defeitos" e pela "ingenuidade" dos filmes do Ciclo do Recife, talvez seja porque estamos cada vez mais desacostumados a representar o nosso próprio passado afamecos

NOTAS 
1. Nossa tradução para : "Des entités surgissent, qui n'ont pas besoin d'être des personnalités complètes: il leur suffit d'avoir des intentions, ou même de coïncider avec elles".

2. Nossa tradução para : «Est un produit de cette forme particulière d'imagination qu' est la fonction fabulatrice. Cette faculté de l'esprit est [à l'origine] du roman, puisque c'est elle qui invente des personnages apparemment doués d'autonomie et qui permet au lecteur d'y croire».Para isso, não existe necessidade de sair da imanência do texto, mas apenas «doter l'objet de dons humains».

3. Nossa tradução para : "Il y a dans le récit, ou plutôt derrière ou devant lui, quelqu' un qui raconte, $c^{\prime}$ est le narrateur. Au-delà du narrateur, il y a quelqu'un qui écrit et qui est responsable de tout son en deçà. Celuilà, grande nouvelle, c'est l'auteur".

4. O conceito de "clássico" foi atribuído a estes dois filmes, entre aspas, por Lucila Ribeiro Bernardet, na dissertação pioneira que defendeu, em 1970, na USP, intitulada "O cinema pernambucano de 1922 a 1931: primeira abordagem".

\section{REFERÊNCIAS}

AUERBACH, E. Mimesis. Paris: Gallimard, 1968.

BORDWELL, D. Narration in the fiction film. London: Methuen, 1985.

BORDWELL D. e THOMPSON K. L'art du film: une introduction. Bruxelles : De Boeck Université, 2002.

BURCH, N. Praxis du Cinéma. Paris: Gallimard, 1969.

DUMORTIER, J.-L. Lire le récit de fiction. Gembloux : Ed. De Boeck-Duculot, 2001.

DUMORTIER, J.-L. et PLAZANET, F. Pour lire le récit. Gembloux : Ed. De Boeck-Duclot, 1986.

GAUDREAULT A. e JOST. F. Le Récit cinématographique. Paris : Nathan, 1990.

GAUDREAULT, A. Du littéraire au filmique : système du récit. Paris: Nathan, 1988.

GENETTE, G. Figures III. Paris: Seuil, 1972.

GUNNING, T. «Le style noncontinu du cinéma des premiers temps», in Cahiers de la Cinematheque, n. 29, hiver 1979, Perpignan.

JOST, F., Un monde à notre image : énonciation, cinéma, télévision. Paris: Méridiens Klincksieck, 1992.

LINTVELT, J. Le roman québécois depuis 1960. Laval : Presses de l'Univesité de Laval, 1992.

METZ, C. l'Énonciation impersonnelle ou le Site du film. Paris: Méridiens Klincksieck, 1991.

MOUREN, Y. Le flash-back: analyse et histoire. Paris: Armand Colin, 2005.

RIBEIRO BERNARDET, L. O cinema pernambucano de 1922 a 1931: primeira abordagem, mimeo, ECA, Universidade de São Paulo, 1970.

RICARDOU, J. Nouveaux problèmes du roman. Paris : Seuil, 1978.

TURIN, M. Flash-back in films, Memory and History. NewYork: Routledge, 1989. 